\title{
Evaluation of the effectiveness of an automated irrigation system using wheat crops
}

\author{
Tahar Boutraa ${ }^{1^{*}}$, Abdellah Akhkha $^{1}$, Abdulkhaliq Alshuaibi $^{1}$, Ragheid Atta $^{2}$ \\ ${ }^{1}$ Department of Biology, Faculty of Sciences, Taibah University, Al Madinah Al Munawarah, \\ Kingdom of Saudi Arabia. \\ ${ }^{2}$ Department of Electrical Engineering, Faculty of Engineering, Taibah University, Al Madinah \\ Al Munawarah, Kingdom of Saudi Arabia. \\ *Correspondence author: Dr Tahar Boutraa - tboutraa@yahoo.co.uk
}

\begin{abstract}
Water stress continues to be one of the most significant environmental factor affecting growth, production and quality of crops worldwide. Improving water agricultural efficiency is crucial in many parts of the world, especially in arid and semi-arid regions, such as Saudi Arabia. The current study investigates the use of an automated irrigation system in comparison with manual irrigation. The plant material used in this study were varieties of wheat (Triticum durum L.) grown in different regions of Saudi Arabia. Plants were grown under two different water irrigation regimes, $80 \%$ and $40 \%$ of the field capacity which are controlled using humidity sensors connected to a micro-controller that detects the water quantity and compensates for water loss in the soil. Plants were grown in $1 \mathrm{~kg}$ capacity plastic pots containing compost mixed with sand (3:1 $\mathrm{v}: \mathrm{v}$ ) and kept in a growth cabinet. The automatic irrigation system performance is evaluated by measuring the growth of plants compared to those of manually irrigated. Growth parameters are shoot, root and total fresh weight and dry weights. No differences were observed in growth, expressed as fresh and dry weights, between the two irrigation systems. Growth showed that total dry weights at both water treatments were higher in the automated system plants than those manually irrigated. The results showed an efficiency of the automated irrigation system over the manual one, as measured by the performance of plants for photosynthesis rates.
\end{abstract}

Keywords: Automated irrigation, manual irrigation, wheat, growth

\section{INTRODUCTION}

More than $40 \%$ of the agricultural lands are under arid or semi-arid climatic conditions (Gamo, 1999). In such environments, water is the most limiting factor in reducing agricultural production. Over the past thirty years many crop breeders and plant physiologists have made great efforts to improve the drought tolerance of a range of agricultural and horticultural crops. One of the main adopted approaches to breeding for drought tolerance to overcome the impacts of water shortage on agricultural production is to concentrate on increasing "water productivity" or "water use efficiency of the crop (Jones, 1993). Other methods focusing on the water conservation techniques can also help in conserving water and supply only water amounts needed by the plants. For example, automated irrigation systems can be very advantageous, especially for looking after plants that grow indoors. If setup and programmed properly, automated irrigation systems can be very economic and also help to conserve water. However, the savings from automatic irrigation systems can go beyond that. Manual irrigation targets plant roots with no significant degree of precision. In contrast, automated irrigation systems can be programmed to discharge more precise amounts of water in a targeted area, which promotes water conservation.

Water Productivity I Water Use Efficiency: The water productivity concept emerged from different fields. In irrigation systems the term water use efficiency has been used to measure the effectiveness of delivered water to crops and the amount of wasted water through this delivery process. The term water use efficiency is based on the assumption that a plant with high water use efficiency should have a greater productivity under water-limited conditions than would a plant with low water use efficiency (Boutraa, 2010). The improvement of water use efficiency is a mean to improve drought tolerance of crops. Crop production may be expressed in terms of the total biomass or seeds weight or even in monetary units when 
production is transferred to monetary units (Ali and Talukder, 2008). The more common way of expressing water productivity is as the ratio of yield to water supply or total evapo-transpiration (evaporation; the loss of water from the soil, and transpiration: is the loss of water from the plant).

WP1 = Grain seed yield / Water applied to the field (kg ha-1 $\mathrm{m}^{-3}$ )

WP2 $=$ Total dry matter yield $/$ Water applied to the field ( $\mathrm{kg} \mathrm{ha}^{-1} \mathrm{~m}^{-3}$ )

WP3 $=$ Total monetary value $/$ Water applied to the field $\left(\$ \mathrm{~m}^{-3}\right)$

Equations (1) and (2) are suitable for the effectiveness of water use in a single crop production, while equation (3) is convenient for the effectiveness of water use in multiple cultures (Ali et al., 2007). Improving water productivity means how we can effectively increase the final crop yield with the water currently in use. Increasing water productivity is an urgent priority in agricultural environments where water is scarce. A number of methods and techniques have been suggested to improve water productivity (Ali and Talikder, 2008; Molden et al., 2010; Passioura, 2006). The use of water for agricultural production in water scarcity regions requires innovative and sustainable research, and an appropriate transfer of technologies. As water supplies become scarce and polluted, there is a need to irrigate more efficiently in order to minimize water use. Efficient water management plays an important role in irrigated agricultural cropping systems. Many areas of agricultural fields are effectively over-or under-irrigated due to spatial variability in water infiltration and runoff of rainfall and irrigation, crop water use and irrigation depth. Under-irrigated areas are subject to water stress, resulting in production loss, while over-irrigated areas suffer from plant disease and nutrient leaching (Pereira et al., 2002).

Improving irrigation efficiency of wheat can contribute greatly to reducing production costs, making the industry more competitive and sustainable. Through proper irrigation, average wheat yields can be maintained (or increased) while minimizing environmental impacts caused by excess applied water and subsequent agrichemical leaching. An automatic irrigation control system is a potential solution to optimize water management by sensing soil water conditions and site-specifically controlling irrigation sprinklers. Recent technological advances have made soil water sensors available for efficient and automatic operation of irrigation systems (Dukes et al., 2005). Automatic soil water sensor-based irrigation seeks to maintain a desired soil water range in the root zone that is optimal for plant growth (Irmak et al., 2001). The target soil water status is usually set in terms of volumetric moisture (expressed in percent of water volume in a volume of undisturbed soil).

Another benefit of automatic irrigation techniques is convenience. In a previous experience working with a soil-moisture-based automatic irrigation system, Dukes et al. (2003) found that once such a system is set up and verified, only weekly observation was required. This type of system adapts the amount of water applied according to plant needs and actual weather conditions throughout the season. This translates not only into convenience for the manager but into substantial water savings compared to irrigation management based on average historical weather conditions. Stone et al. (1985) presented a computer-based monitoring system for continuous measurements of soil water potential. Zazueta and Smajstrla (1992) compared indirect estimates with direct measurement of soil moisture. Meron et al. (2001) used a control system for apple tree irrigation management using tensiometers. Testezlaf et al. (1997) used an automated irrigation control system for management of greenhouse container plants. An automated irrigation system was proposed for remote infield sensing and variable-rate irrigation control (Kim et al., 2008). The system requires seamless integration of the system input and output components, and software design for decision support and monitoring.

Recent advances in soil water sensing can make the commercial use of this technology possible to automate irrigation management for wheat production. However, research indicates that different sensors types may not perform alike under all conditions (Smajstrla and Locascio 1996). Reductions in water use range as high as $70 \%$ compared to farmer practices with no negative impact on crop yields. The automatic irrigation system is based on the feedback of the soil water status to maintain soil water content with a specific range. Tensiometers and granular matrix sensors (GMS) were the first types of sensors used for automatic irrigation control (Muñoz-Carpena and Dukes, 2008). Many systems have been developed for this purpose; For example, Zhao et al. (2008) developed a system base on evapo-transpiration that can instruct 
automated irrigation in greenhouses. Automated systems can also be used for other purposes other than irrigation; for example, Eberlein et al. (2000) developed a linear-move irrigation system equipped with an automated irrigation control system to be used in site-specific herbigation; it was proven to be very efficient in weed control.

The objective of this paper is to describe a userfriendly simple and cheap design for continuous monitoring of soil water level and automatically irrigate the plants according to their needs of previously set water level. The system consists of humidity sensor, sensor driver, and water controller.

\section{MATERIALS AND METHODS}

The humidity sensor: The circuit uses a humidity sensor which changes its capacitance with the change in the relative humidity $(\mathrm{RH})$ level. The humidity sensor is connected as a part of a pulse width modulation system which changes the width of the output pulse width with the change in $\mathrm{RH}$. The output modulated pulse is filtered and averaged to transform the change in the pulse width into change in the DC level which is a direct reading of the $\mathrm{RH}$ level. This output is fed into a comparator which compares the $\mathrm{RH}$ level with a preset value according to the required plants water level. The output of the comparator will activate a relay that is connected to an electric tap which allows the water to irrigate the plants till the sensor reaches the set level. A schematic block diagram of an automated irrigation system for variable-rate irrigation is illustrated in diagram. 1.

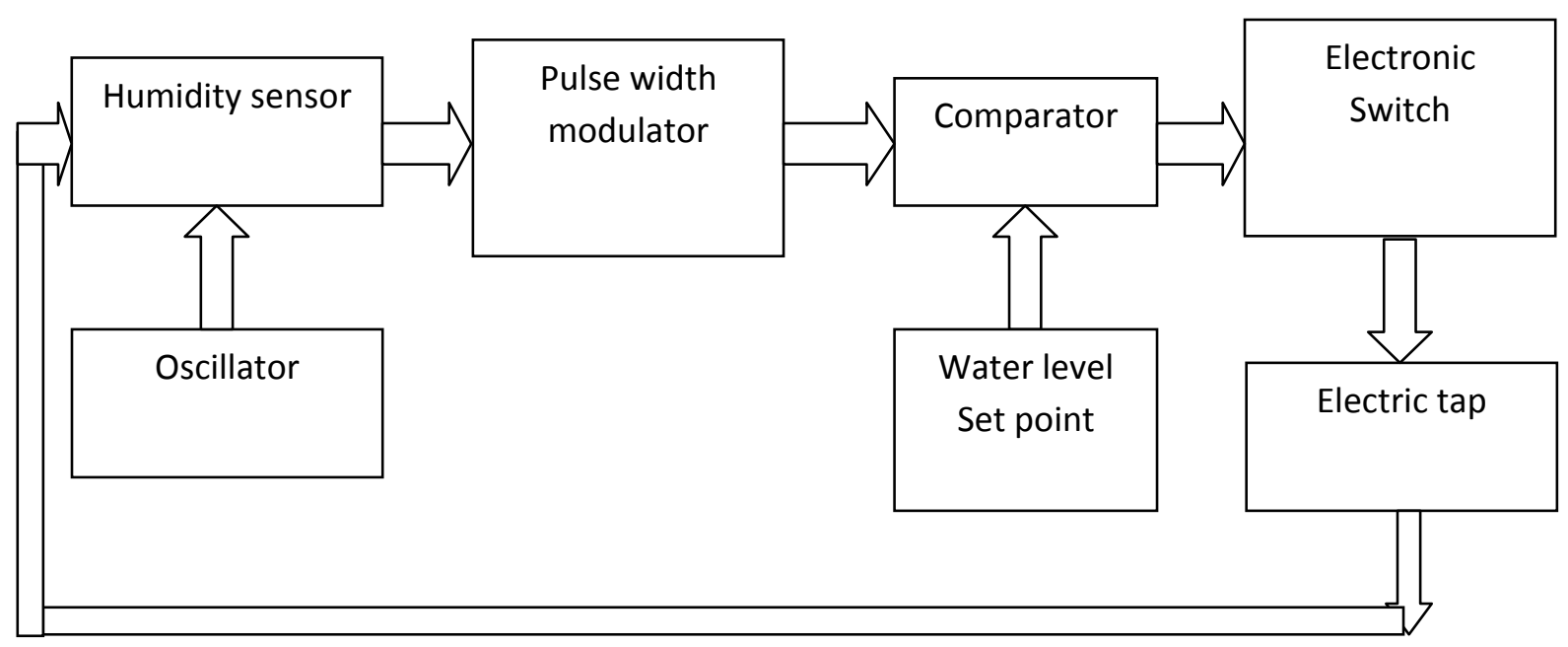

Diagram1. Circuit block diagram of the designed automated irrigation system.

Using such a simple system allows the water level to be kept at a certain preset value all the time. This preset water level value can be changed if needed at a certain stage of plant growth. Due to the soil's natural variability, location and number of soil water sensors may be crucial and future work should include optimization of sensor placement. Additional research should also include techniques to overcome the limitation of requiring a soil specific calibration

Plants growth: The study was conducted in the Department of Biology, Faculty of Sciences at Taibah University in Al-Madinah Al-Munawarh, Kingdom of Saudi Arabia. Seeds of wheat cultivar (Triticum durum), Hab Ahmar, were used in this study. Seeds were sown in $12 \mathrm{~cm}$ plastic pot containing soilcompost (1:3 v:v). Pots were maintained at full irrigation for two weeks before starting the application of water treatment. After two weeks plants were divided into two groups, one were irrigated manually, whereas the second group were irrigated automatically using the electrical sensor. Two treatments of water regimes were applied; $80 \%$ of the field capacity (FC) and $40 \%$ of the FC. For plants irrigated manually, pots were weighed every 1-2 days, and irrigated to restore the soil to the appropriate moisture regime by adding calculated amount of water to reach the appropriate water level; $80 \%$ or $40 \%$ of the FC. For plants irrigated automatically, irrigation was maintained by the automatic electronic sensor itself. At the end of the experiment plant height were measured. Plants were harvested to estimate growth by measuring shoot and root fresh weight and dry weight. Physiological 
measurements were made to estimate the rate of photosynthesis.

Statistical Analysis: The means and standard errors (shown in graphs) were calculated using Excel (Microsoft Office 2007). Analysis of variance was performed using Minitab's ANOVA and General Linear Model (version 13).

\section{RESULTS AND DISCUSSION}

Effect on Plant Height: The results of the effect of manual and automatic irrigation were summarized and plotted in Fig. 1. Plants irrigated manually or automatically showed no significant differences $(p>$ 0.05). Plant heights of roses controlled by a computer program for automatic watering were slightly higher than those manually irrigated (Wen-jin et al., 2010).

Effect on Plant Fresh Weight: The effect of manual and automatic irrigation on plant fresh weight including shoot, root and total fresh weight was investigated. There was a slightly significant $(p<$ 0.05 ) decrease in shoot fresh weight of the automatic $40 \%$ compared to that of manually irrigated plants. However, no significant difference $(p>0.05)$ was shown in $80 \%$ of both irrigation types in Fig. 2 . Fresh weight of aerial parts of rose plants irrigated by automatic watering controlled by a computer program were slightly higher than those under ordinary irrigation conditions with no significant differences between the two systems (Wen-jin et al., 2010). Fig. 3 showed a slightly $(p<0.05)$ decrease in root fresh weight, in the $40 \%$ manually irrigated plants compared to that of the automatically irrigated plants. The $80 \%$ water regime showed no significant $(p>$ 0.05 ) difference between both types of irrigation. A number of studies have reported a reduction of shoot growth under deficit irrigation conditions (Gowing et al., 1990; Dry and Loveys, 1998). A slight decrease $(p<0.05)$ in total fresh weight, shown in Fig. 4, was observed in $40 \%$ water treatment of automatically irrigated plants, whereas the $80 \%$ showed no significant $(p<0.05)$ difference in total fresh weight between the two types of irrigation. Phene and Howell (1984) used soil matric sensor to control surface drip irrigation system to irrigate tomato plants. They found that yield of the automated tomatoes of the automated system were similar to those of tomatoes plants irrigated based on pan evaporation evaporation with less water used for irrigation. Using switching tensiometeplaced at $15 \mathrm{~cm}$ depth reduced water requirements for tomato plants by $40-50 \%$ without reducing yield (Smajstrla and Locascio, 1996).

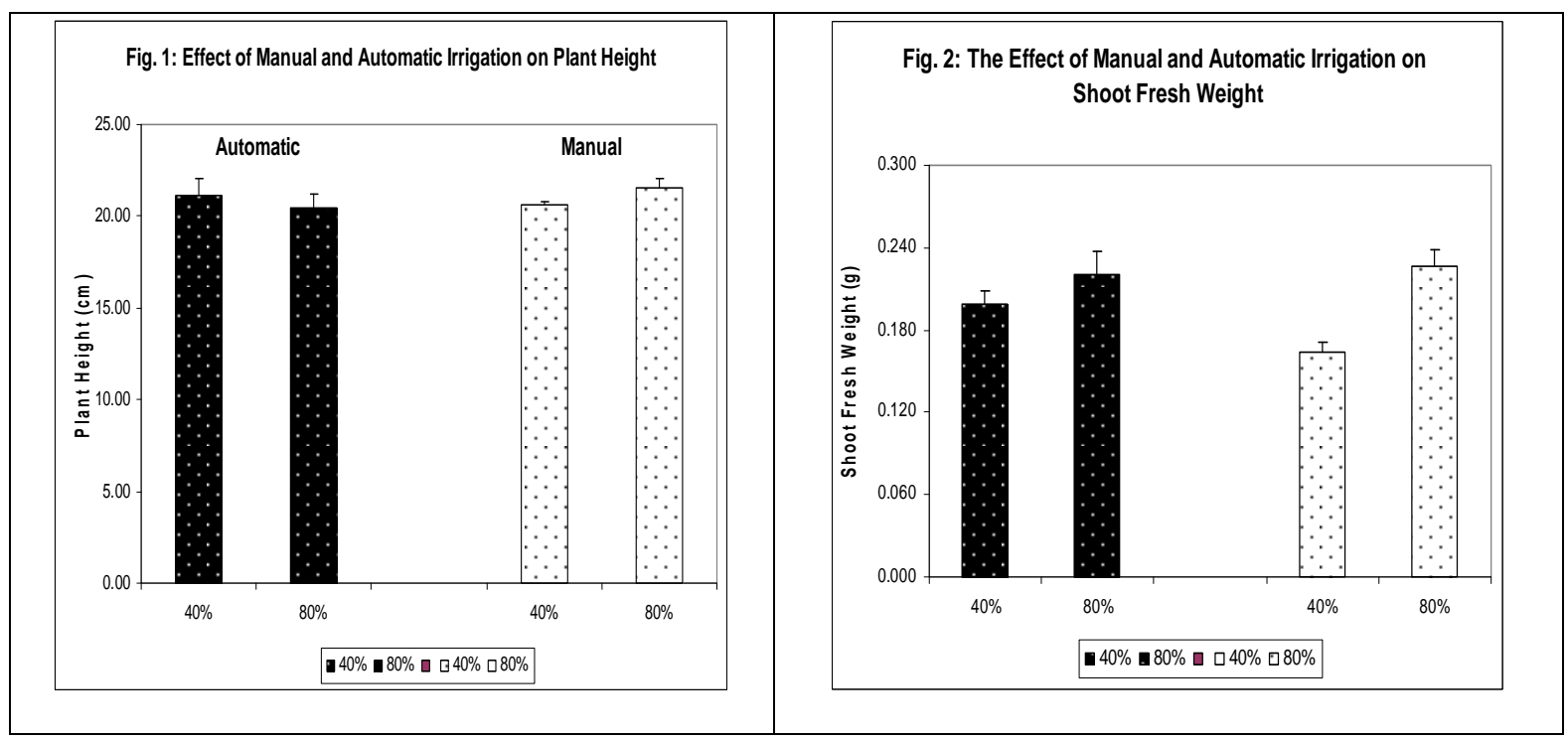




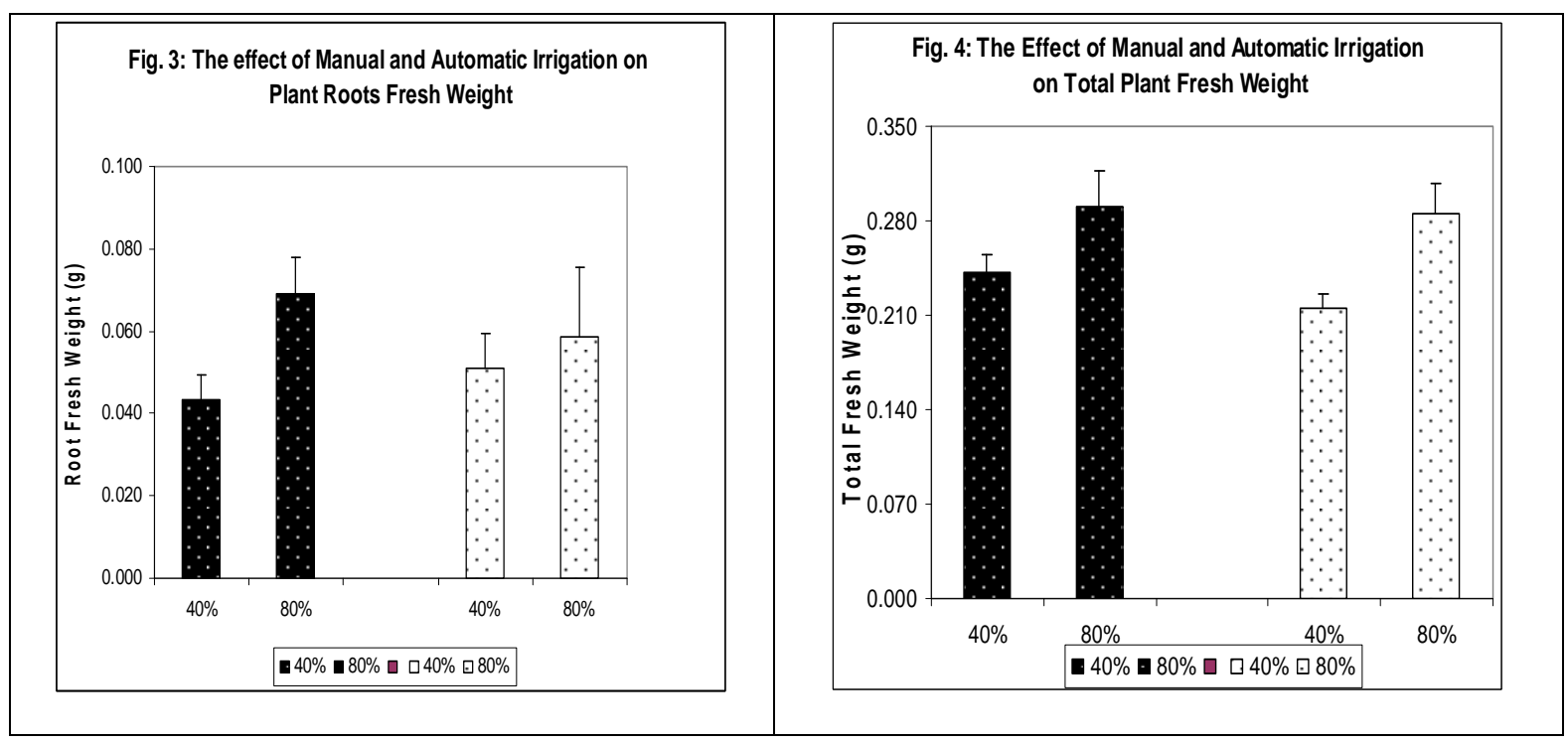

Effect on Plant Dry Weight: Growth of plants was investigated through the measurements of shoot, root and total dry weights, as shown in Figs. 5, 6 and 7 . The shoot dry weights of plants manually irrigated were significantly $(p<0.05)$ higher at $40 \%$ water regime compared to that of $80 \%$ water regime. However, no significant difference $(p>0.05)$ was detected at $80 \%$ between automatically and manually irrigated plants. A slight decrease $(p<0.05)$ was found in root dry weight of plants automatically irrigated at $40 \%$ (Fig. 6). However, no significant difference was detected in the $80 \%$ water regime. Overall, growth showed that total dry weights at both water treatments are higher in automatically irrigated plants than those manually irrigated (Fig. 7). GuangCheng et al. (2010) found that total dry weight of time space deficit irrigation (TSDI) irrigated pepper were $1.17-30.66 \%$ lower than that of non-stressed plants. However, TDW of plants exposed to water stress followed by normal watering were not significantly different from that of non-stress control plants.

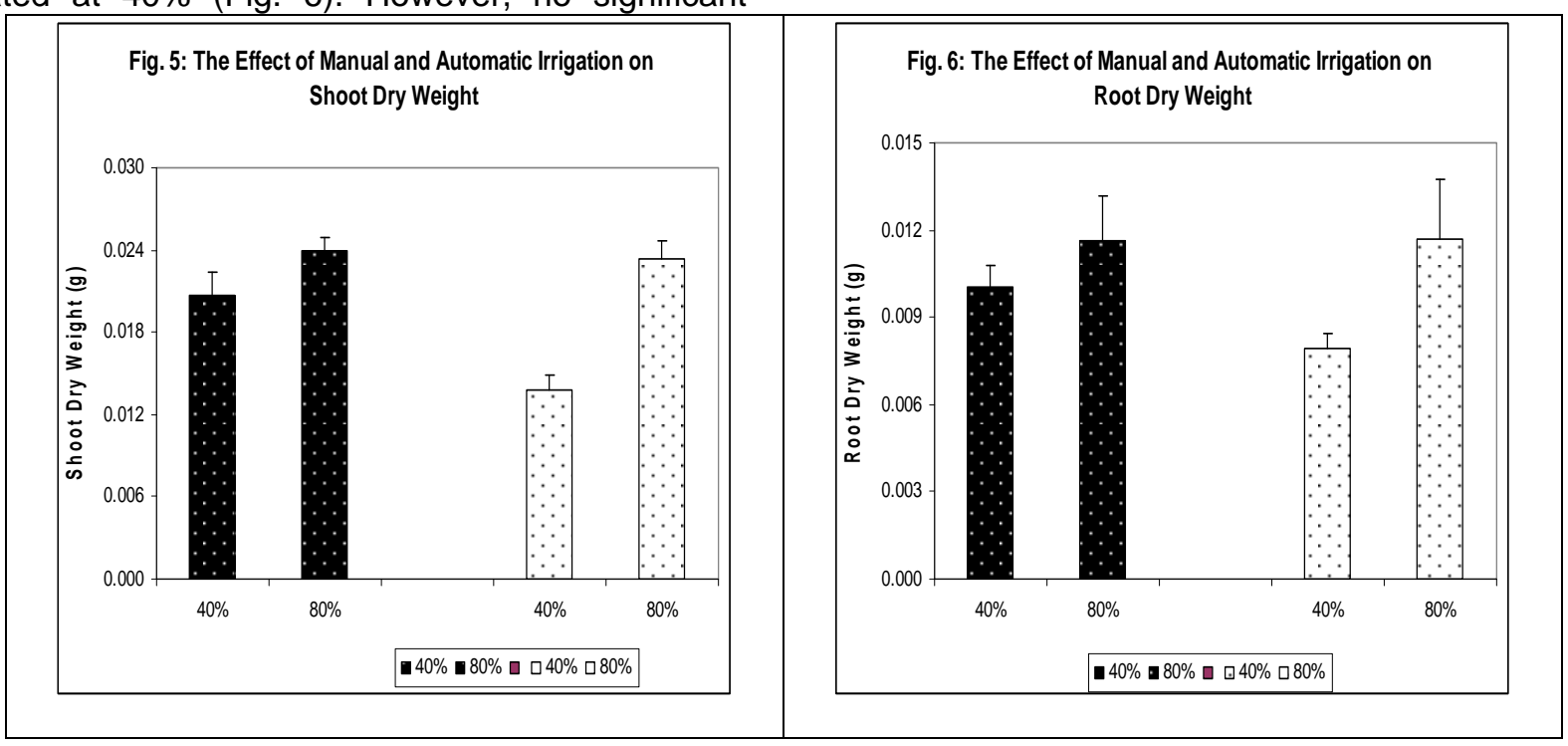




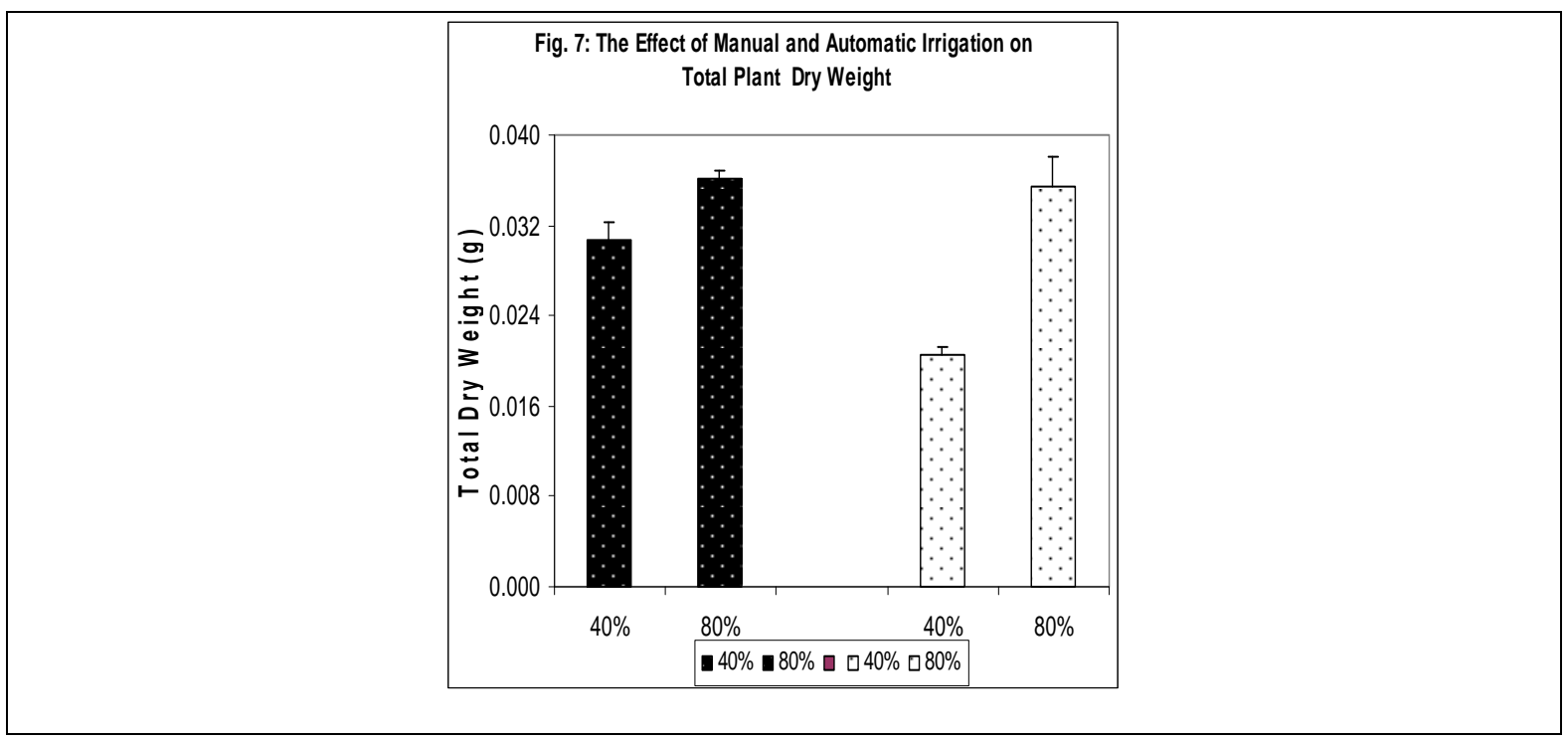

Effect on Plant Photosynthesis: The photosynthesis, the process by which plants make their food (biomass) that will be used for growth and economically important yield, grain filling in cereals including wheat. The rates of photosynthesis were determined in both manually and automatically irrigated plants in order to relate the biomass accumulation expressed as dry weight to the photosynthesis rates. The results showed that photosynthesis rates declined earlier $(1000 \mu \mathrm{mol}$ quanta) in manually irrigated plants $(40 \%)$, as shown in Figs. 8 and 9.

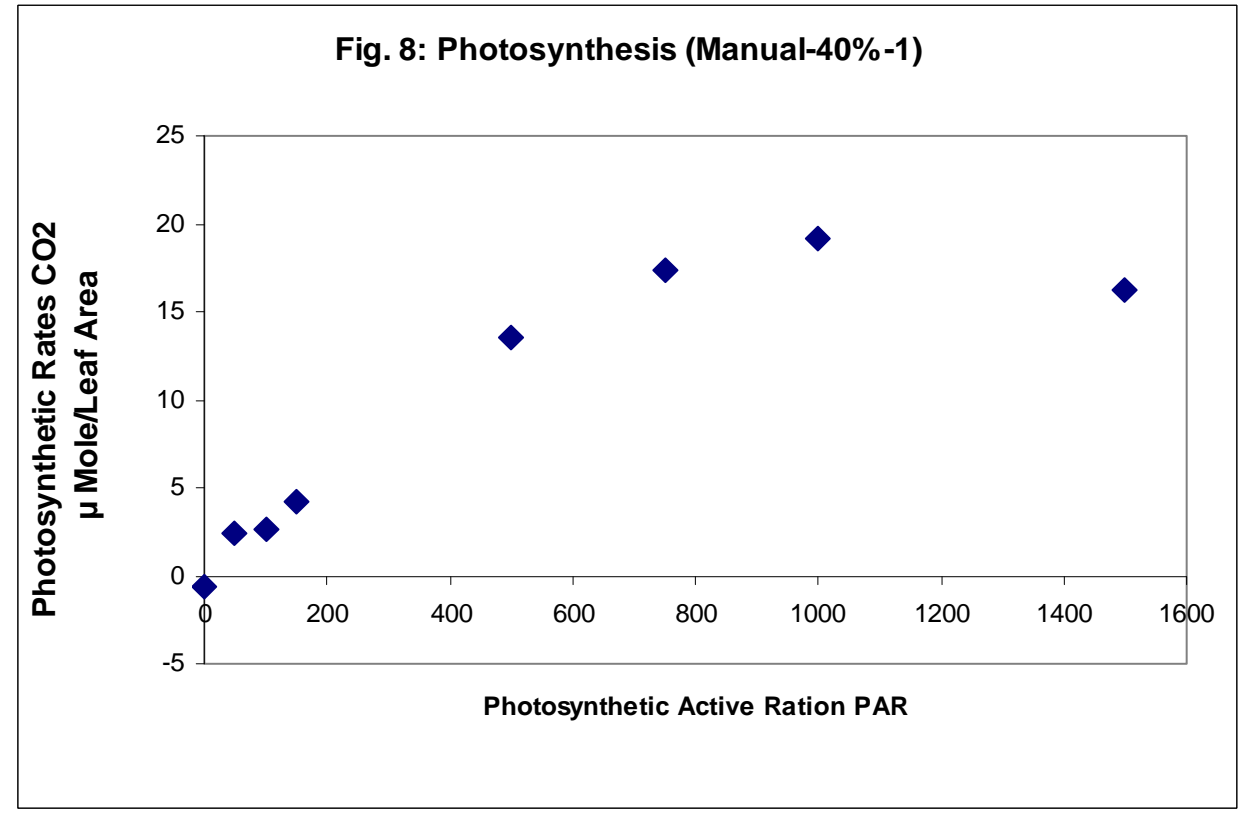


Agric. Biol. J. N. Am., 2011, 2(1): 80-88

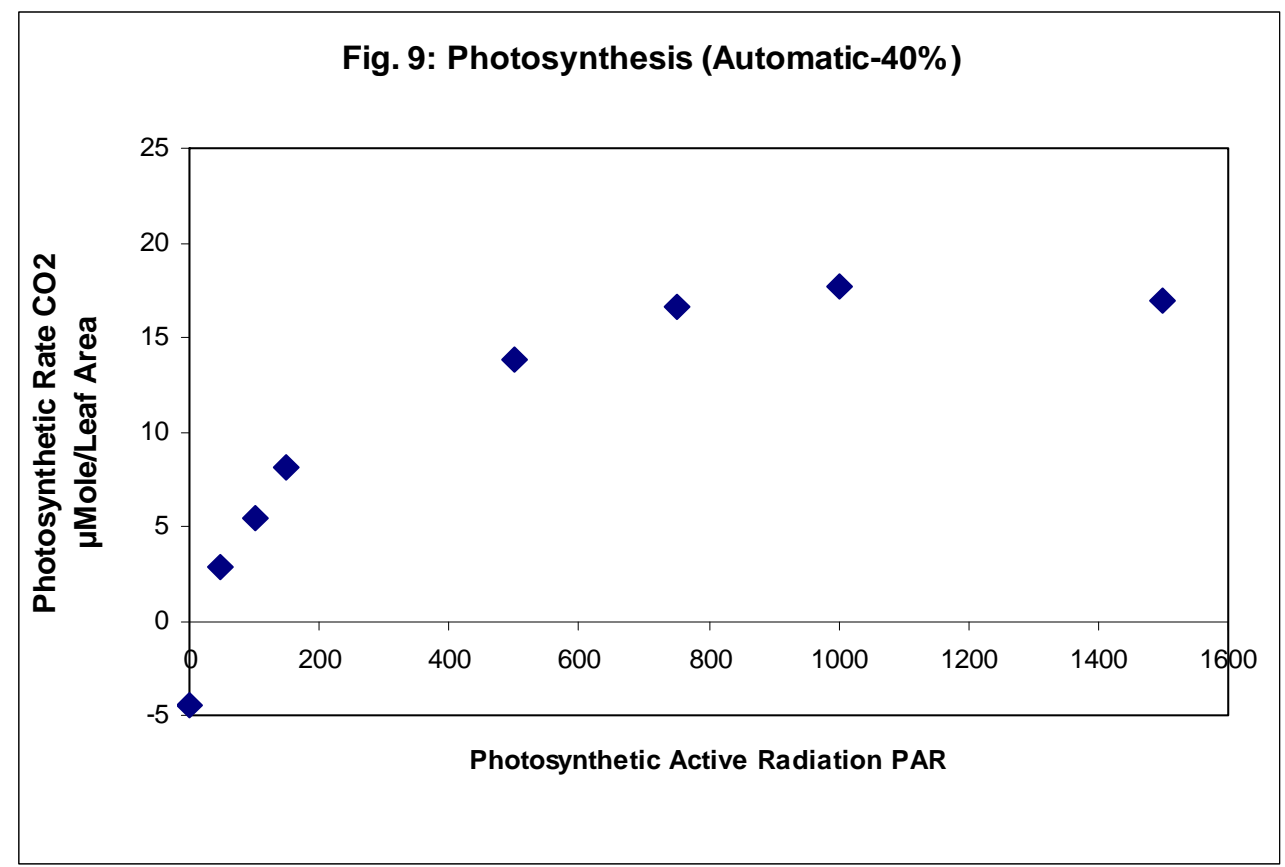

At $40 \%$ water treatment, the photosynthesis rate declined significantly $(p<0.05)$ in plants irrigated manually, while in plants irrigated by the automatic system had no decline, and this was observed even at $1500 \mu \mathrm{mol}$ quanta of photosynthesis active radiation (PAR). This decline in the manually irrigation at $80 \%$ water level can be explained by the occurrence of photoinhibition, the slowing or stopping of the photosynthesis process by light, as shown in Figs. 10 and 11. Because of high demand of water to plants, photosynthesis rates, and subsequently growth and yield, are decreased when water becomes limited. Zotarelli and Dukes (2010) found that photosynthesis rates were reduced by the drier irrigation treatments, based on-demand irrigation controllers, with a threshold by the soil field capacity level. They also reported that relative photosynthesis rate of bell pepper increased with increase of relative water saving using soil moisture sensors.

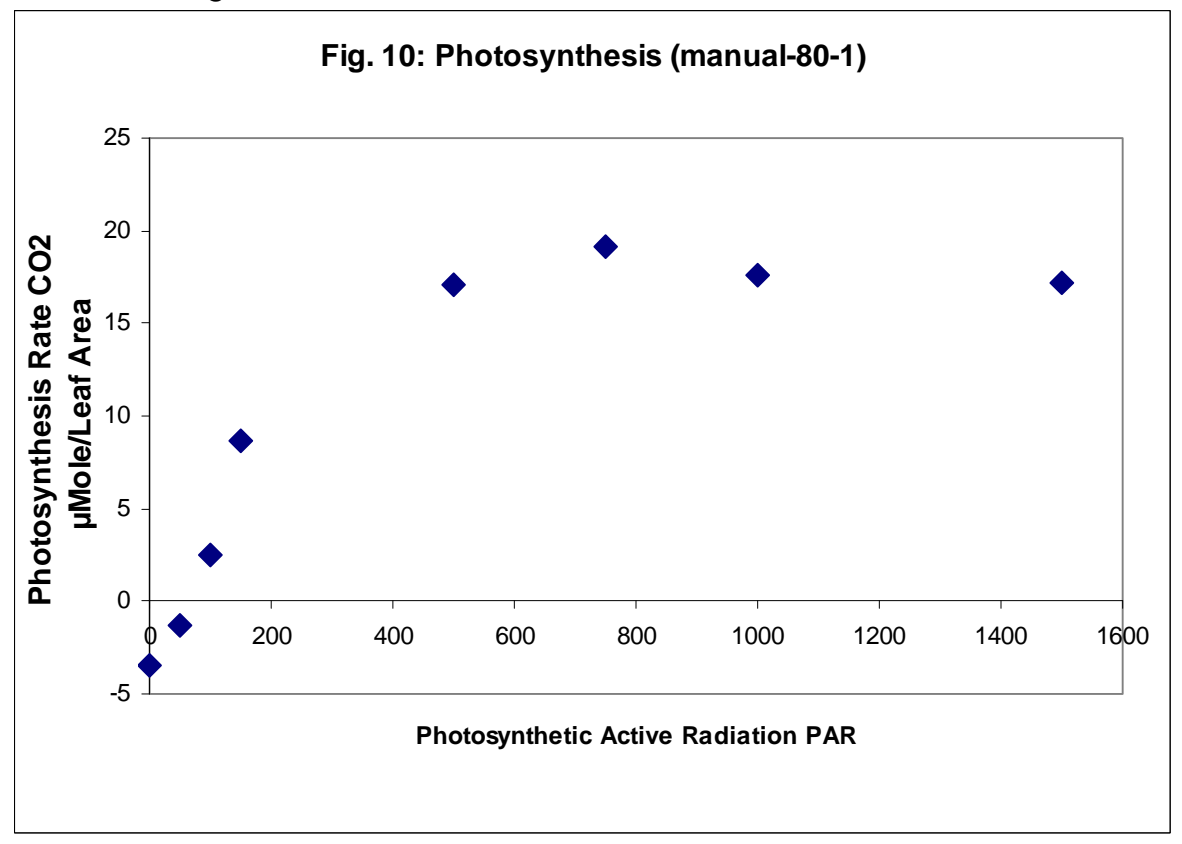




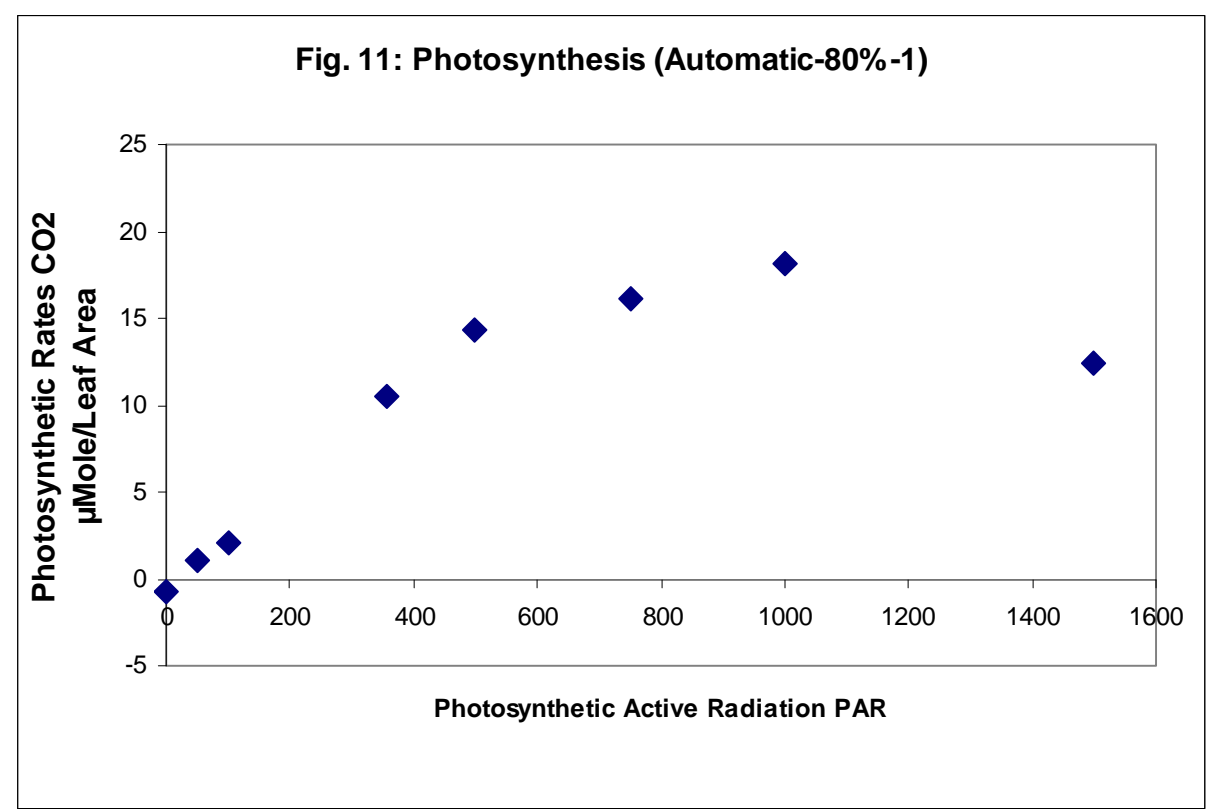

\section{CONCLUSIONS:}

It has been reported that drip irrigation by tensiometers and granular matrix sensors (GMS) to irrigate tomatoes saved water when compared with typical irrigation practices (Muñoz-Carpena et al., 2005). Research in the field of irrigation technology shows promising results in water savings. For example, Dukes et al., (2003) also found that 50\% reduction in water use in pepper plants using soil water based automatically irrigation system in comparison to daily manually irrigated treatments. It has also been reported that $11 \%$ irrigation savings with drip irrigation compared to sprinkler irrigation (Dukes and Scholberg, 2005). Preliminary results of the current study indicated that wheat plants automatically irrigated have a higher photosynthesis rates compared to those manually irrigated, which might be an indication of higher plant biomass and hence higher yield production. Further work is required to repeat this type of investigations and future research should be carried out on a larger scale to determine the efficiency of automatic irrigation over manual irrigation.

\section{REFERENCES:}

Ali, M.H. and Talukder, S.H.U (2008). Increasing water productivity in crop production - A synthesis. Agricultural Water Management, 95, 1201-1213.

Ali, M.H., Hoque, M.R., Hassan, A.A and Khair, M.A (2007). Effects of deficit irrigation on yield, water productivity, and economic returns of wheat. Agricultural Water Management, 92,151-161.

Boutraa, T (2010). Improvement of water use efficiency in irrigated agriculture: A review. Journal of Agronomy, 9, 1-8.

Guang-Cheng, S., Na, L., Zhan-Yu, Z., Shuang-En, Y and Chang-ren, C (2010). Growth, yield and water use efficiency response of greenhouse-grown hot pepper under Time-Space deficit irrigation. Scientia Horticulturae, 126, 172-179.

Dukes, M.D and Scholberg, J.M (2005). Soil moisture controlled subsurface drip irrigation on sandy soils. Applied Engineering in Agriculture, 21, 89-101.

Dukes, M.D., Simonne, E.H., Davis, W.E., Studstill, D.W and Hochmuth, R (2003). Effect of sensor-based high frequency irrigation on bell pepper yield and water use. Proceedings of $2^{\text {nd }}$ International Conference on Irrigation and Drainage, May 12-15. Phoenix, AZ. pp. 665-674.

Dukes, M.D., Simonne, E.H., Davis, W.E., Studstill, D.W and Hochmuth, R (2003). Effect of sensor-based high frequency irrigation on bell pepper yield and water use. Proceedings of $2^{\text {nd }}$ International Conference on Irrigation and Drainage, May 12-15, Phoenix, AZ., 665674.

Gamo, M (1999). Classification of arid regions by climate and vegetation. Journal of Arid Land Studies, 1, 9-17.

Irmak, S and Haman, D.Z (2001). Performance of the Watermark granular matrix sensor in sandy soils. Applied Engineering in Agriculture, 17, 787-795. 
Jones, H.G (1993). Drought tolerance and water-use efficiency, in: Water deficits: plant responses from cell to community. Smith, J.A.C. and Griffiths, H. Editors, Bios Scientific Publishers, Oxford, 193-203.

Kim, Y., Evans, R.G and Iversen, W.M (2008). Remote sensing and control of an irrigation system using a distributed wireless sensor network. IEEE Trans. Instrum. Meas., 57, 1379-1387.

Meron, M., Hallel, R., Peres, M., Bravdo, B., Wallach, R and Gieling, T (2001). Tensiometer actuated automatic micro irrigation of apples. Acta Horticulturae, 562, 6369.

Molden, D., Oweis, T., Steduto, P., Bindraban, P., Hanjr, M.A and Kijne, J (2010). Improving agricultural water productivity: Between optimism and caution. Agricultural Water Management, 97, 528-535.

Muñoz-Carpena, R and Dukes, M.D (2008). Automatic Irrigation Based on Soil Moisture for Vegetable Crops. Extension Bul., AE354 of the Dept of Agricultural and Biological Engineering, University of Florida. http://edis.ifas.ufl.edu/pdffiles/AE/AE35400.pdf

Muñoz-Carpena, R., Dukes, M.D., Li, Y.C and Klassen, W (2005). Field comparison of tensiometer and granular matrix sensor automatic drip irrigation on tomato. HortTechnology, 15, 584-590.

Passioura, J (2006). Increasing crop productivity when water is scarce - from breeding to field management. Agricultural Water Management, 80, 176-196.

Pereira, L.S., Oweis, T. and Zairi, A (2002). Irrigation management under water scarcity. Agricultural Water Management, 57, 175-206.

Phene, C.J and Howell, T.A (1984). Soil sensor control of high frequency irrigation systems. Transactions ASAE, 27, 392-396.

Smajstrla, A.G. and Locascio, S.J (1996). Tensiometercontrolled drip irrigation scheduling of tomato. Applied Engineering in Agriculture, 12, 315-319.
Smajstrla, A.G and Locascio, S.J (1996). Tensiometercontrolled drip irrigation scheduling of tomato. Applied Engineering in Agriculture, 12, 315-319.

Stone, K.C., Smajstrla, A.G and Zazueta, F.S (1985). Microcomputer-based data acquisition system for continuous soil water potential measurements. Soil Crop Sci. Soc. Fla. Proc., 44, 49-53.

Testezlaf, R., Zazueta, F.S and Yeager, T.H (1997). A realtime irrigation control system for greenhouses. Applied Engineering in Agriculture, 13, 329-332.

Zazueta, F.S and Smajstrla, A.G (1992). Microcomputerbased control of irrigation systems. Applied Engineering in Agriculture, 8, 593-596.

Zotarelli, L and Dukes, M.D (2010). Evaluation and Demonstration of Soil Moisture Based On-demand Irrigation Controllers for Vegetable Production. Final report B228 of the Dept of Agricultural and Biological Engineering, University of Florida. http://www.swfwmd.state.fl.us/files/database/site_file_s ets/42/Soil- Sensors- SWFWMD_B228-FinalReport_03302010.pdf

Wen-jin, Y., Ryo, K., Katsuhiko, K., Lian-hua, L and Hirokazu, K (2010). A Computer program for automatic watering based on potential evapotranspiration by Penman method and predicted leaf area in miniature pot rose production. Agricultural Sciences in China, 9, 370-377.

Zhao, C., Zhang, Y., Wang, C., Qiao, X., Hao, R and Yang, Y (2008). Research of Greenhouse Efficient Automatic Irrigation System Based on Evapotranspiration. Computer and Computing Technologies in Agriculture, 2, 1047-1054.

Eberlein, C.V., King, B.A and Guttieri, M.J (2000). Evaluating an Automated Irrigation Control System for Site-Specific Herbigation. Weed Technology, 14(1), 182-187. 